\title{
Pancreatobiliary-Type Malignant Cells Present
}

National Cancer Institute

\section{Source}

National Cancer Institute. Pancreatobiliary-Type Malignant Cells Present. NCI Thesaurus.

Code C95964.

A morphologic finding indicating the presence of malignant cells with a phenotype that resembles the malignant cells of the pancreatic ductal or extrahepatic bile duct carcinomas. 